\title{
The chemical composition, antioxidant activity, and antiproliferative activity of selected seed flours
}

\author{
Zhangyi Song ${ }^{\mathrm{a} \dagger}$, Yanfang $\mathrm{Li}^{\mathrm{b} \dagger}$, Boyan $\mathrm{Gao}^{\mathrm{b}}$, Jihye Lee ${ }^{\mathrm{a}}$, Yanbei Wu${ }^{\mathrm{c}}$, Jianghao Sun ${ }^{\mathrm{d}}$, \\ Monica Whent ${ }^{\mathrm{a}^{*}}$, Pei Chen ${ }^{\mathrm{d}}$, Seong-Ho Lee ${ }^{\mathrm{a}}$ and Liangli Yu ${ }^{\mathrm{a}}$ \\ aDepartment of Nutrition and Food Science, University of Maryland, College Park, MD 20742, United States \\ bInstitute of Food and Nutraceutical Science, School of Agriculture and Biology, Shanghai Jiao Tong University, Shanghai 200240, China \\ ${ }^{\mathrm{c} B e i j i n g}$ Advanced Innovation Center for Food Nutrition and Human Health, Beijing Technology \& Business University, Beijing 100048, \\ China \\ ${ }^{\mathrm{d} F o o d}$ Composition and Methods Development Laboratory, Beltsville Human Nutrition Research Center, Agricultural Research Service, \\ United States Department of Agriculture, Beltsville, MD 20705, United States \\ †These authors contributed equally to the work. \\ *Corresponding author: Monica Whent, Department of Nutrition and Food Science, University of Maryland, College Park, MD 20742, \\ USA. Tel: +1 301 4054521; E-mail: mwhent@umd.edu \\ DOI: $10.31665 /$ JFB. 2020.10230 \\ Received: June 08, 2020; Revised received \& accepted: June 24, 2020 \\ Citation: Song, Z., Li, Y., Gao, B., Lee, J., Wu, Y., Sun, J., Whent, M., Chen, P., Lee, S.-H., and Yu, L. (2020). The chemical composition, \\ antioxidant activity, and antiproliferative activity of selected seed flours. J. Food Bioact. 10: 77-85.

\section{Abstract} \\ The phytochemicals in broccoli, carrot, and milk thistle seed flours were extracted with ethanol. Their chemi- \\ cal composition, free radical $\left(\mathrm{ABTS}^{+}\right.$and $\mathrm{DPPH}^{\circ}$ ) scavenging, and anti-proliferative capacity were evaluated. Si- \\ lychristin, glucoraphanin, and kaempferol-3-O-rutinoside were the primary components in milk thistle, broccoli, \\ and carrot seed flour extract, respectively. The total phenolic contents of milk thistle, broccoli, and carrot seed \\ flour extracts were 16.9, 8.4, and $1.8 \mathrm{mg}$ gallic acid equivalent/g seed flour, respectively. The seed flour extracts \\ demonstrated antioxidant activity against $\mathrm{DPPH}^{\circ}$ and $\mathrm{ABTS}^{+}$. Milk thistle extract demonstrated antiproliferative \\ activity against colon cancer cells. These findings could promote the utilization of the seed flours to add health \\ value to foods.
}

Keywords: LC-MS; Carrot seed; Milk thistle seed; Broccoli seed; Functional food.

\section{Introduction}

Vegetable and herb seed flours are the by-products of seed oil production. Typically, the seed flours are discarded after the oil has been extracted. If seed flours contain health-beneficial properties, these flours can be valuable ingredients in nutraceuticals and functional foods. In this scenario, the seed oil production companies can benefit from increased use of the flour and waste can be reduced (Balasundram et al., 2006).

Previous studies have demonstrated that vegetable seed flours contain various antioxidant phytochemicals. Phenolic compounds have been found in broccoli, carrot, and milk thistle seed flours, including quercetin-3-glucoside, luteolin, and silymarin, respec- tively (Choe et al., 2018; Omar et al., 2012). Phenolic compounds possess the ability to donate hydrogen atoms and chelate metal ions, which gives them antioxidant activity (Balasundram et al., 2006). It is well known that oxidation reactions can cause damage to different tissues in human bodies, such as DNA, proteins, and lipids (Lobo et al., 2010). This damage may eventually lead to chronic disease, including cancer, liver disease, cardiovascular disease, and diabetes (Higashi et al., 2009; Paz-Elizur, et al., 2008; Rains and Jain, 2011). Antioxidant compounds can inhibit the oxidation reaction by interrupting the free-radical chain reaction in lipid oxidation or scavenging singlet oxygen. (Damodaran et al., 2008). Therefore, foods that contain antioxidant components may help to prevent some chronic diseases (Lobo et al., 2010). 
The components of vegetable seed flours have previously demonstrated health enhancing properties. Glucoraphanin is one major glucosinolate found both in the broccoli and its seed flour (Choe et al., 2018; Moreno et al., 2006). It can be converted to sulforaphane by myrosinases in the plant or by other myrosinases and microbials in the colon (Juge et al., 2007). Sulforaphane has been shown to inhibit the growth of Helicobactor pylori, a bacteria that increases the risk of gastritis and gastric cancer. Sulforaphane was also shown to prevent tumor growth induced by benzo $[a]$ pyrene and inhibit breast cancer and prostate cancer cells (Fahey et al. 2002; Y. Li et al., 2010; S. V. Singh, et al., 2005). Milk thistle seed flour is rich in silymarin which is a class of compounds including silychristin, silydianin, silybin A \& B, and isosilybin A \& B (Wallace et al., 2005). It has been reported that silymarin has hepatoprotective activity, and anticancer activity against skin, prostate, and lung cancers (Deep and Agarwal, 2007; Mateen et al., 2010). Carrot seeds have been shown to have antioxidant, hepatoprotective, and anti-inflammatory activity (Singh et al., 2012; Vasudevan et al., 2006). Luteolin is a component of carrot seed flour that has demonstrated anti-cancer properties (Imran et al., 2019).

While some health promoting properties of seed flours have been identified, the complete chemical composition of seed flours has not yet been studied extensively. The research on milk thistle seed flower has focused on silymarins, with few studies of the other compounds in milk thistle seed flour. Previous studies usually evaluated the whole seeds instead of seed flours after oil extraction. Acetone and methanol aqueous solutions have most often been selected as the extraction solvents. (McWalter et al., 2004; Choe et al., 2018).

In this study, ethanol extracts of broccoli, carrot, and milk thistle seed flours after cold pressing were investigated for their chemical composition, antioxidant, and anti-proliferative activity. Ethanol with a concentration over $95 \%(\mathrm{v} / \mathrm{v})$ is easier to recover than other solvents during oil extraction. Hence, the extraction solvent in this study is more practical for seed production companies.

\section{Materials and methods}

\subsection{Seed flours}

Broccoli, carrot, and milk thistle seed flour samples were provided by Botanic Oil Innovation (Spooner, WI, USA). The seed flours were the remains from the cold-pressing process.

\subsection{Chemicals}

( \pm -6-Hydroxy-2,5,7,8-tetramethyl-chromane-2-carboxylic acid (Trolox), fluorescein (FL), 2,2'-azino-bis(3-ethylbenzothiazoline6-sulfonic acid) diammonium salt (ABTS), 2,2-diphenyl-1-picrylhydrazyl (DPPH), gallic acid and Folin \& Ciocalteu's phenol reagent (FC) were all purchased from Sigma-Aldrich (St. Louis, MO, USA). Ethanol, 3-(4,5-dimethylthiazol-2-yl)-2,5-diphenyltetrazolium bromide (MTT), and dimethyl sulfoxide (DMSO) were purchased from Fisher Scientific (Pittsburgh, PA, USA). Dulbecco's Modified Eagle Medium (DMEM) was purchased from Corning Inc. (Corning, NY, USA). Fetal bovine serum was purchased from Hyclone Laboratories Inc. (Logan, UT, USA).

\subsection{Sample preparation}

Each ground seed flour sample (1.5 g) was accurately weighed, ex- tracted with $15 \mathrm{ml}$ of $100 \%$ ethanol using a Soxhlet extractor for 3 hours, and filtered through Whatman No.1 filter paper. The filtrate was transferred to a $25 \mathrm{ml}$ volumetric flask, diluted with $100 \%$ ethanol to volume, and mixed. All experiments were performed in triplicate.

\subsection{Total phenolic contents}

The ethanol extracts of seed flour were analyzed for their total phenolic content using Folin-Ciocalteu (FC) reagent with a previously described procedure (Stevanato et al., 2004). The final reaction mixture consisted of $250 \mu \mathrm{l} \mathrm{FC} \mathrm{reagent,} 750 \mu 120 \%$ sodium carbonate, $50 \mu \mathrm{l}$ seed flour extract (or standard, or blank solvent control), and $3.0 \mathrm{ml}$ ultrapure water. The absorbance at $765 \mathrm{~nm}$ was measured after 2 hours of reaction at ambient temperature. Gallic acid was used as the standard in concentrations of 50, 100, 200, 400, and $800 \mu \mathrm{g} / \mathrm{mL}$. Experiments were carried out in triplicate.

\subsection{ABTS $^{+}$scavenging capacity}

The scavenging capacities of the seed flour extracts were measured against $\mathrm{ABTS}^{+}$generated using a chemical method according to a published protocol (Moore et al., 2006). The working solution of $\mathrm{ABTS}^{+}$was prepared by oxidizing the solution of ABTS with manganese dioxide in ambient temperature for $30 \mathrm{~min}$ and then diluted to $0.700 \pm 0.005$ at $734 \mathrm{~nm}$. The final reaction mixture contained $1.0 \mathrm{ml}$ of $\mathrm{ABTS}^{+}$working solution and $100 \%$ ethanol as control or $80 \mu \mathrm{l}$ of the tested sample or standard solution (Trolox). After vortexing for $30 \mathrm{~s}$, the mixture was measured for its absorbance at $734 \mathrm{~nm}$ after $90 \mathrm{~s}$ of reaction. The standard curve was set using concentrations of $0.01,0.02,0.04,0.06$, and $0.08 \mu \mathrm{mol}$ Trolox $/ \mathrm{mL}$. Experiments were conducted in triplicate.

\subsection{Relative $\mathrm{DPPH}^{\bullet}$ scavenging capacity}

The relative $\mathrm{DPPH}^{\bullet}$ scavenging capacities (RDSC) of the seed flour extracts were evaluated using an assay described by Cheng and others (Cheng et al., 2006). The procedure of this assay involved a Victor ${ }^{3}$ multilabel plate reader. To start the reaction, $100 \mu \mathrm{l}$ of $0.2 \mathrm{mmol} / \mathrm{L}$ DPPH was mixed with the Trolox standard, blank solvent control, or the samples. The absorbance was read at $515 \mathrm{~nm}$ every minute for 1.5 hours. The $\mathrm{DPPH}^{*}$ scavenging capacities were derived from the areas under the curve. Experiments were conducted in triplicate.

\subsection{Ultra high-performance liquid chromatography photo di- ode array high-resolution multi-stage mass spectrometry (UH- PLC-PDA-ESI/HRMS ${ }^{n}$ )}

The UHPLC-HRMS analysis was performed by an LTQ Orbitrap XL mass spectrometer (Thermo Scientific, Waltham, MA, USA) equipped with an Agilent 1290 Infinity liquid chromatography linked with a DAD detector as it was reported by Choe et al. (2018). The scanning range of the UV-vis spectrum was 190-600 $\mathrm{nm}$. The separations were conducted on a $4.6 \mathrm{~mm}$ i.d. $\times 250 \mathrm{~mm}$, $5 \mu \mathrm{m}$ particle size Luna C18 column. A gradient mobile phase of HPLC-grade water (solvent A) and acetonitrile (solvent B) both containing $0.1 \%$ formic acid $(\mathrm{v} / \mathrm{v})$ has the flow rate of $1.0 \mathrm{ml} / \mathrm{min}$. The gradient elution started with $5 \%$ of solvent B. Then solvent B was increased to $13 \%$ at $5 \mathrm{~min}$ through a linear gradient followed by being increased to $20 \%$ at $10 \mathrm{~min}$. After that solvent B was increased to $27 \%$ at $25 \mathrm{~min}$, followed by increasing to $33 \%$ at 40 


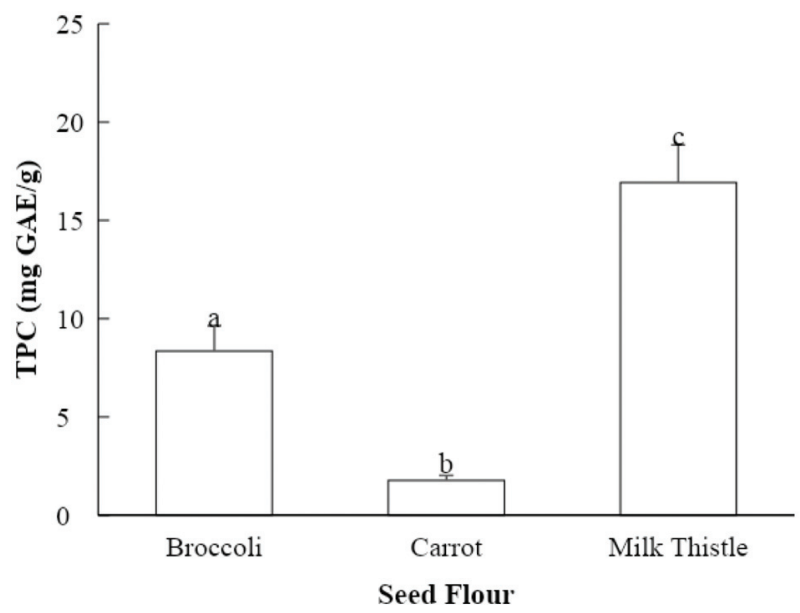

Figure 1. Total phenolic content (TPC) of seed flour samples (mg GAE/g seed flour). Values marked by different letters are significantly different $(P<0.05)$.

min. Then solvent $\mathrm{B}$ was increased to $50 \%$ at $45 \mathrm{~min}$ and increased to $90 \%$ at $46 \mathrm{~min} .90 \%$ of solvent B was kept until $51 \mathrm{~min}$ and then the $10 \mathrm{~min}$ post-run time was carried out for re-equilibration. The injection volume was set as $5 \mu$. The oven temperature was $40^{\circ} \mathrm{C}$. The compounds were analyzed under a negative ionization mode. The heated capillary temperature was set at $325^{\circ} \mathrm{C}$, capillary voltage at $-50 \mathrm{~V}$, spray voltage at $4.5 \mathrm{kV}$, then tub lens offset voltage at $-120 \mathrm{~V}$. The full scan covered the range from $\mathrm{m} / \mathrm{z} 100$ to 2,000 with the resolution of 30,000 . The data was then postprocessed using QualBrowser part of Thermo Scientific Xcalibur 2.2 software.

\subsection{Antiproliferative activity}

The selected seed flour extracts were evaluated for their anti-proliferative capacity using colorectal cancer (CRC) cells (HCT116, SW480) and 3T3-L1 preadipocytes. CRC cells $\left(5 \times 10^{3}\right.$ cells per well) were cultured at $37{ }^{\circ} \mathrm{C}$ under $5 \%$ carbon dioxide in DMEM supplemented with $10 \%$ fetal bovine serum and $1 \%$ penicillin/streptomycin. After $18 \mathrm{~h}$, the cells were treated with media containing the seed flour extract final concentration of $60 \mu \mathrm{g}$ flour equivalent per $\mathrm{ml}$ in the culture mixture for 24 and $48 \mathrm{~h}$. After that, the supernatant was removed and the mixture of MTT and serum-free media (1:5, $\mathrm{v} / \mathrm{v}$ ) was added. After $3 \mathrm{~h}$, DMSO was added and the absorbance at $540 \mathrm{~nm}$ was measured. Experiments were carried out in triplicate.

\subsection{Statistical analysis}

Data were reported as mean \pm standard deviation (SD) for each point. A one-way analysis for variation (ANOVA) with Tukey's post-hoc test was performed with IBM SPSS Statistics (Version Rel. 22.0.0.0, IBM Inc., Armonk, NY) to identify the significant differences among means. Statistical significance was declared at $P<0.05$.

\section{Results and discussion}

\subsection{Total phenolic content}

The total phenolic content (TPC) of milk thistle seed flour extract

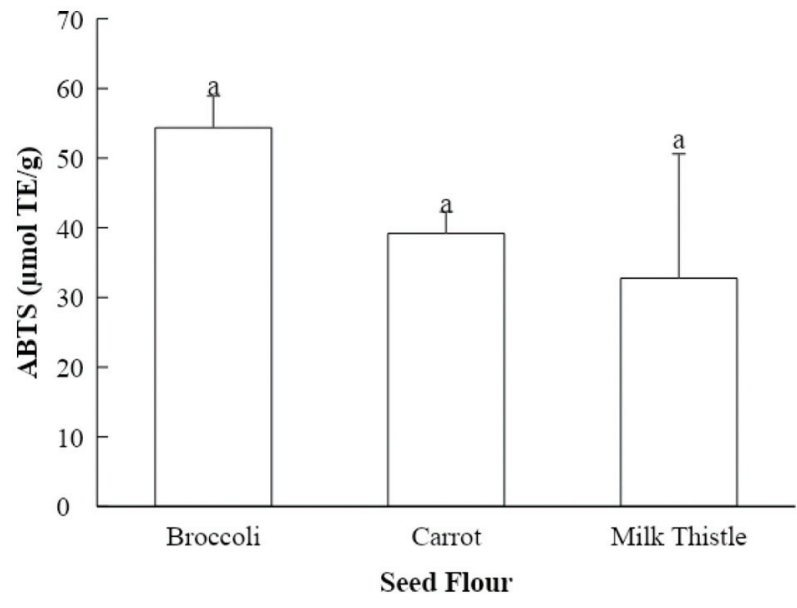

Figure 2. $\mathrm{ABTS}^{+}$scavenging capacities of seed flour samples ( $\mu \mathrm{mol} \mathrm{TE} / \mathrm{g}$ seed flour). Values marked by different letters are significantly different $(P<0.05)$

was $16.9 \mathrm{mg} \mathrm{GAE} / \mathrm{g}$ of seed flour and that of broccoli seed flour extract was $8.4 \mathrm{mg}$ gallic acid equivalent $(\mathrm{GAE}) / \mathrm{g}$ of seed flour. Carrot seed extract exhibited TPC levels of 1.8 of seed flour (Fig. 1). Parry and others reported that the TPC of $50 \%$ acetone extract of milk thistle seed flour was $25.2 \mathrm{mg} \mathrm{GAE} / \mathrm{g}$ seed flour (Parry et al., 2008), which is higher than that found in the current study.

The evaluation of phenolic content using Folin-Ciocalteau reagent is commonly used for plant extracts. This method may be less accurate when samples have a high content of ascorbic acid or if there are biological impurities in the extract (Sánchez-Rangel et al., 2013). However, it remains an accepted method to estimate phenolic content. The TPC of milk thistle seed flour extract in the current study may be lower than that in the study by Parry et al. due to differences in the extraction solvents or in the growing conditions of the plants.

\subsection{Antioxidant activity}

The $\mathrm{ABTS}^{+}$scavenging capacities of the seed flour samples ranged from 32.8 to $54.4 \mu \mathrm{mol}$ TE per g of seed flour (Fig. 2). Broccoli seed flour extract had the highest value for $\mathrm{ABTS}^{+}$scavenging capacity $(54.4 \mu \mathrm{mol} \mathrm{TE} / \mathrm{g}$ of seed flour) among the evaluated seed flours. Carrot seed flour extract had the second highest $\mathrm{ABTS}^{+}$ scavenging capacity $(39.2 \mu \mathrm{mol} \mathrm{TE} / \mathrm{g}$ of seed flour), followed by the milk thistle seed flour extract $(32.8 \mu \mathrm{mol} \mathrm{TE} / \mathrm{g}$ of seed flour $)$ (Fig. 2). The seed flour extracts did not have statistically significant differences in $\mathrm{ABTS}^{+}$scavenging capacity. Previously, the $\mathrm{ABTS}^{+}$scavenging capacity of $50 \%$ acetone extracts of broccoli, carrot, and milk thistle seed flour was measured by Choe et al., and the values were 175.9, 250.0, and $116.2 \mu \mathrm{mol} \mathrm{TE} / \mathrm{g}$ (Choe et al., 2018; Choe et al., 2019). The stronger $\mathrm{ABTS}^{+}$scavenging capacity found by Choe et al. could be related to differences in extraction solvents, as mentioned above.

The seed flour samples in the current study all exhibited relative $\mathrm{DPPH}^{*}$ scavenging capacity (RDSC) (Fig. 3). The RDSC method evaluates the scavenging of $\mathrm{DPPH} \cdot$ compared to the tocopherol analogue Trolox. Broccoli seed flour extract had the highest RDSC value of $19.4 \mu \mathrm{mol}$ Trolox equivalent (TE)/g of seed flour, followed by milk thistle seed flour extract ( $10.0 \mu \mathrm{mol} \mathrm{TE} / \mathrm{g}$ of seed flour). Carrot seed flour extract exhibited lower RDSC value of $3.3 \mu \mathrm{mol} \mathrm{TE} / \mathrm{g}$ of seed flour. However, the differences in these values did not show statistical significance. Previous studies showed that $50 \%$ acetone $(\mathrm{v} / \mathrm{v})$ 


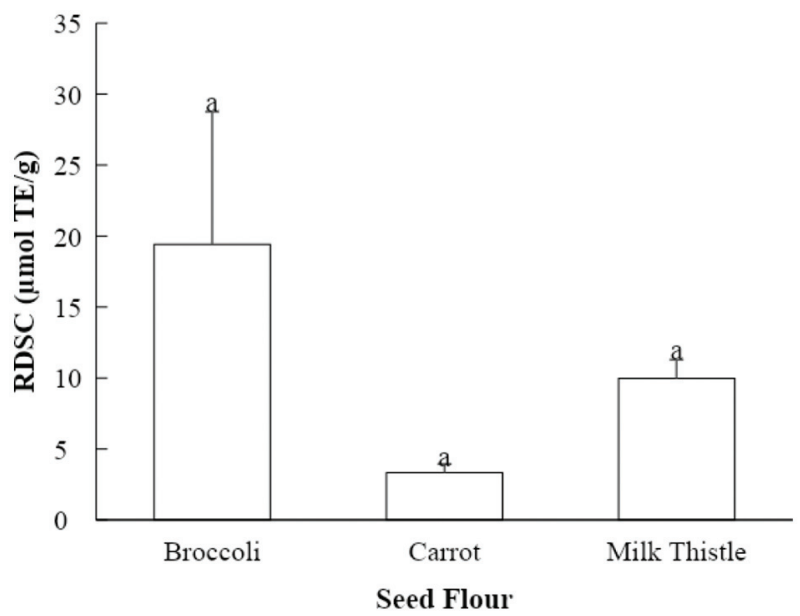

Figure 3. Relative DPPH' scavenging capacities (RDSC) of seed flour samples ( $\mu \mathrm{mol} \mathrm{TE} / \mathrm{g}$ seed flour). Values marked by different letters are significantly different $(P<0.05)$.

extracts of broccoli, carrot, and milk thistle seed flour possessed the RDSC values of $84.8,16.0$, and $48.6 \mu \mathrm{mol} \mathrm{TE} / \mathrm{g}$, respectively (Choe et al., 2018; Choe et al., 2019). Parry and others extracted the milk thistle seed flour with $50 \%$ acetone $(\mathrm{v} / \mathrm{v})$ as well and reported the RDSC level to be $61.1 \mu \mathrm{mol}$ TE/g (Parry et al., 2008). The values acquired by Choe et al. and Parry et al. were both higher than those in the current study. The RDSC of pumpkin and parsley seed flour extracts evaluated by Parry and others was 2.2 and $18.1 \mu \mathrm{mol} \mathrm{TE} / \mathrm{g}$, respectively (Parry et al., 2008). Parsley seed flour extract from that study had similar RDSC value to that of broccoli seed flour in the current study. Parry and others evaluated the acetone extracts of mullein and cardamom seed flours, and found that the RDSC was 21.2-24.0 and $19.5 \mu \mathrm{mol}$ TE/g (Parry et al., 2008). The DPPH' scavenging capacities of these two seed flours were stronger than that of milk thistle seed flour from the current study.

Apart from the differences in cultivars and growing conditions, an important factor affecting the varying antioxidant capacity might be the extraction solvent. Ayoub and others found that when acetone was applied as a solvent, the extracted phenolic yield was higher compared to methanol used as the extraction solvent (Ayoub et al., 2016). Because ethanol is similar in structure and properties to methanol, it is reasonable to assume ethanol also has less extraction ability than acetone. Hence, the change of extracting solvent may alter the values obtained from antioxidant assay and explain why the RDSC values from the current study were lower than those in other studies.

It was reported in previous studies that there was a significant correlation between the total phenolic content and antioxidant assays including $\mathrm{ABTS}^{+}$scavenging capacity and relative $\mathrm{DPPH}^{\circ}$ scavenging capacity (da Silva, et al., 2016; de Camargo et al., 2015). In the current study, the milk thistle seed flour extract had the highest total phenolic content. Broccoli seed flour showed the highest antioxidant capacity using the selected methods but did not show a statistically significant difference from the milk thistle seed flour.

\subsection{Chemical composition}

Eight chemical compounds were provisionally identified in the broccoli seed flour, which included glucoraphanin isomers, glucoerucin, sinapoylhexose, disinapoylgentiobiose, 1,2-disinapoyl- glucoside, and 1,2,2'-trisinapoylgentiobiose (Table 1 and Fig. S1). In a previous study, McWalter et al. analyzed the glucosinolates in defatted broccoli seed extracted with methanol. Sinigrin, gluconapin, progoitrin, glucoiberin, glucoraphanin, glucoalyssin, and gluconasturtiin were detected in the extract of broccoli seed flour (McWalter et al., 2004). Choe et al. analyzed 50\% acetone extract of broccoli seed flour. A total of nine chemical compounds were detected in the extract, eight of which were the same as reported in this study. Choe et al. (2018) detected one additional chemical, quercetin-3-glucoside. The difference in the glucosinolates composition of the broccoli seed flour in this study compared to the others could be due to the different extracting solvents and extraction methods, and different cultivars and growing conditions.

Ten chemical compounds were tentatively identified in the carrot seed flour, including caffeoyldihexoside, cistanoside F, lycibarbarphenylpropanoid $\mathrm{C}$, kaempferol-3- $O$-rutinoside isomers, apigenin-7-O- $\beta$-D-rutinoside, diosmetin-7-rutinoside, kaempferol-3-O-glucoside isomer, and luteolin. Kaempferol-3-O-rutinoside and luteolin were two primary chemicals identified (Table 2 and Fig. S2).

Luteolin, luteolin 3'-O- $\beta$-D-glucopyranoside, and luteolin 4 '-O- $\beta$-D-glucopyranoside were identified in $60 \%$ methanol $(\mathrm{v} / \mathrm{v})$ extract of the carrot seed by Kumarasamy and others (Kumarasamy et al., 2005). The compounds identified were similar to those in the current study, because luteolin was one of the greatest peaks in the UHPLC chromatogram of the carrot seed extract. A previous study by Choe et al. (2018) used 50\% acetone (v/v) to extract carrot seed flour. They identified the same compounds as those in this study. The comparison with the previous findings shows that ethanol is an adequate extraction solvent to identify the chemical components of carrot seed flour.

A total of 13 chemical compounds were tentatively identified in the milk thistle seed flour, including chlorogenic acid and its isomers, 5- $p$-(6-caffeoyl-glucopyranosyl)-coumaroylquinic acid isomers, methyl 5-(6-Caffeoyl-glucopyranosyl)-caffeoylquinic acid, taxifolin, silychristin isomers, silybin A, silybin B, and isosilybin (Table 3 and Fig. S3). Wallace and others extracted defatted milk thistle seed flour with boiling ethanol $\left(79^{\circ} \mathrm{C}\right)$ for $10 \mathrm{~h}$ to achieve maximum yields. They detected silymarin, taxifolin, silychristin, silydianin, silybinin A and silybinin B with HPLC. (Wallace, et al., 2005). The chemical compositions of two sources of milk thistle seeds were extracted with $100 \%$ methanol and analyzed by Mudge and others. Silychristin, silydianin, silybin A, silybin B, isosilybin A, and isosilybin B were detected (Mudge et al., 2015). Choe et al. identified several major chemicals in milk thistle seed flour as well. The seed flour was extracted with $50 \%$ acetone $(\mathrm{v} / \mathrm{v})$ using sonication. The major compounds identified were silychristin, silybin A, silybin B, and isosilybin A \& B (Choe et al., 2019). The silymarin composition identified in the ethanol extracts of the current study is consistent with the major components identified in previous studies. The presence of chlorogenic acid and its derivatives is also consistent with the findings of Choe (Choe et al., 2019).

The components identified in the seed flours have previously been shown to have potential effects on human health. Glucophoranin from broccoli seed is converted to sulphorophane, which has demonstrated effects against cancer growth (Fahey et al., 2002; Li et al., 2010). Luteolin from carrot seed and silymarin from milk thistle seed have also shown anti-cancer activity in previous studies (Imran et al., 2019; Deep and Agarwal, 2007; Mateen et al., 2010). The identification of these components shows the potential for the seed flours to add health value in foods. Further studies on the feasibility of using these flours in functional foods would be beneficial. 


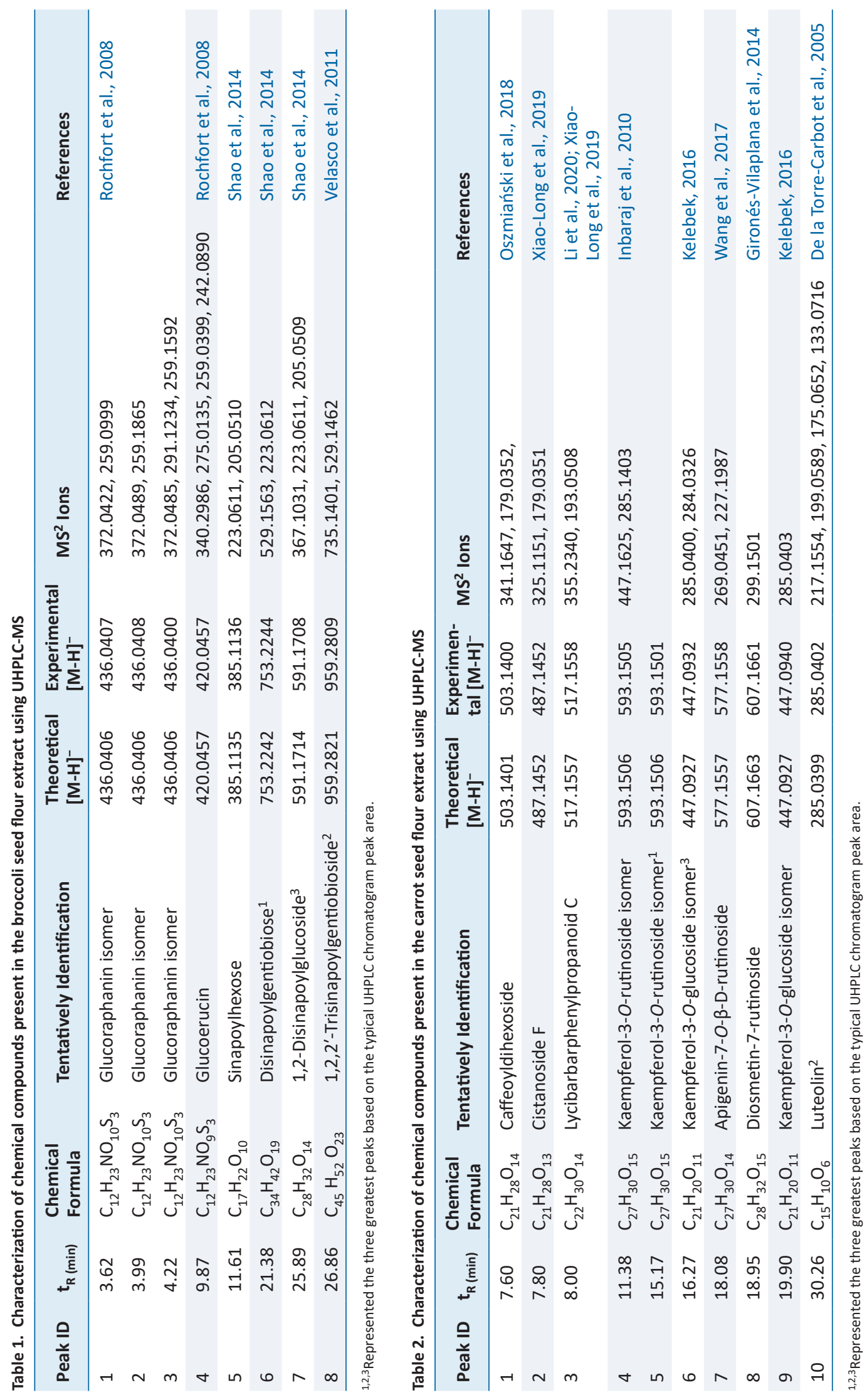




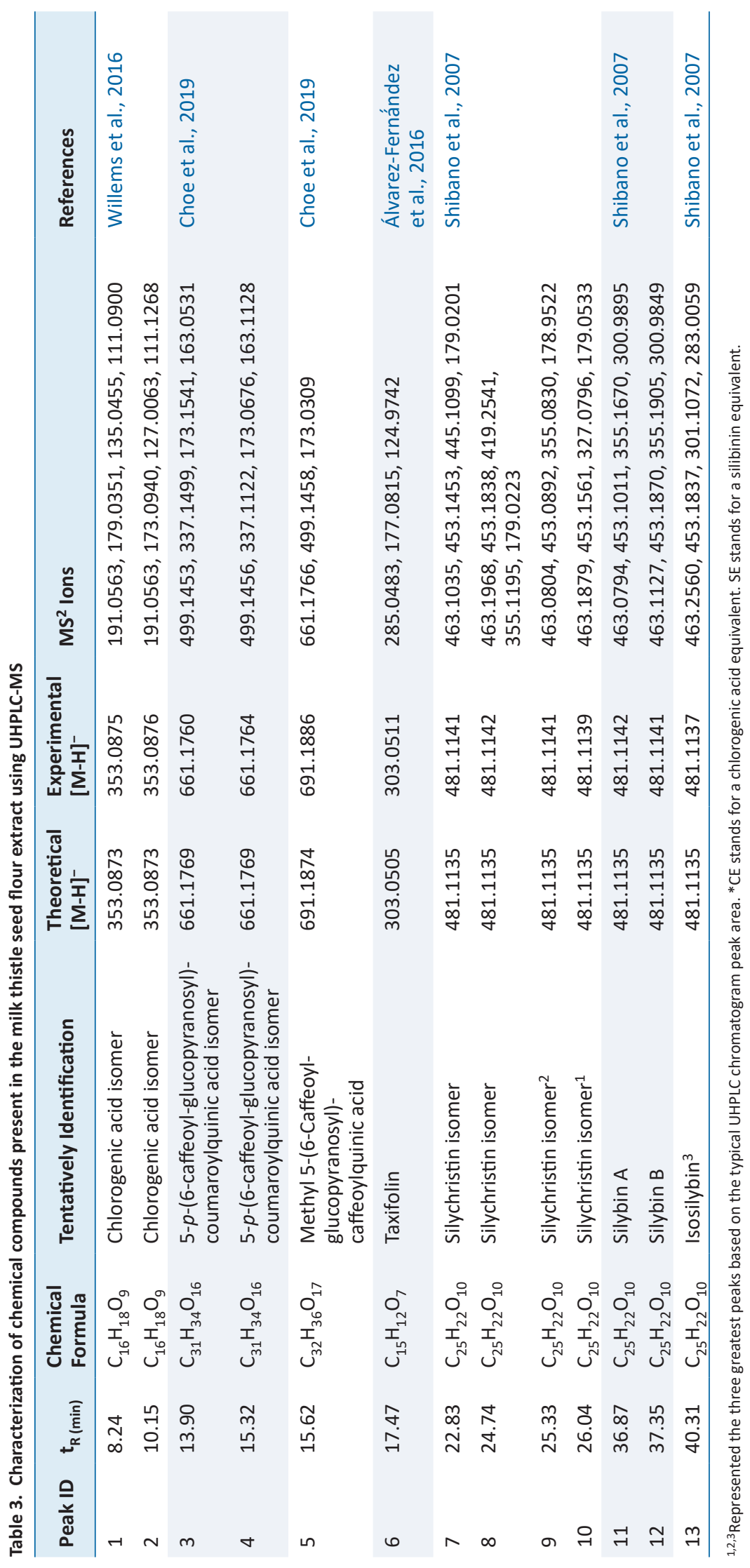


a

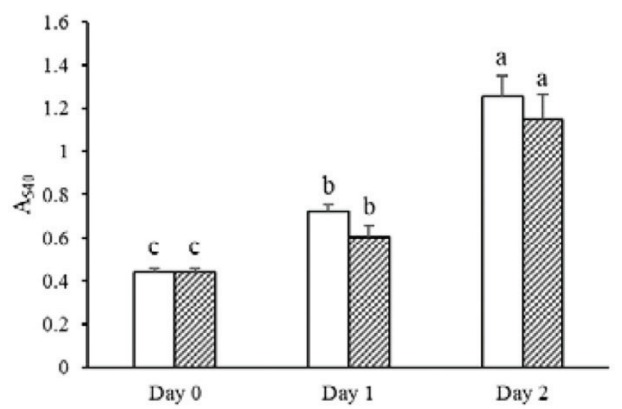

C

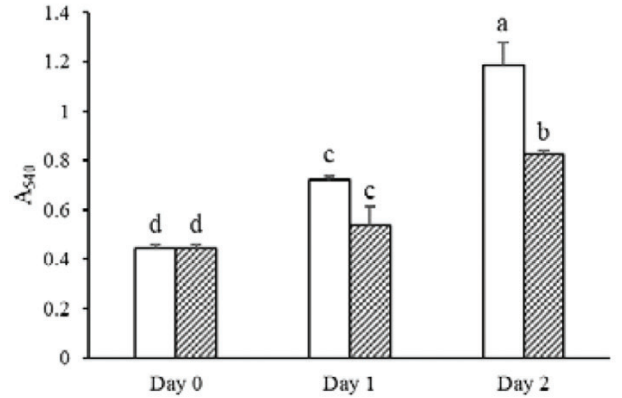

b

$\square 0 \mu \mathrm{g} / \mathrm{ml}$

⿶60 $\mu \mathrm{g} / \mathrm{ml}$

$\square 0 \mu \mathrm{g} / \mathrm{ml}$

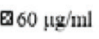

$\square 0 \mu \mathrm{g} / \mathrm{ml}$

$060 \mathrm{~g} / \mathrm{ml}$

Figure 4. Cell toxicity in 3T3-L1 preadipocytes for selected seed flour extracts. Different letters within the same day represent significant difference $(P<$ 0.05).

\subsection{Antiproliferative activity}

The cell toxicity of broccoli, carrot, and milk thistle seed flours were tested on 3T3-L1 preadipocytes, to measure potential anti-obesity effects of the extracts. Of the tested seed flour extracts, only the milk thistle seed flour showed cell toxicity at the concentration of $60 \mu \mathrm{g}$ seed flour equivalent per $\mathrm{ml}$ (Fig. 4). A higher concentration of seed flour extract may be needed to show effects from the other extracts.

As shown in Figure 5, broccoli and carrot seed flours had no antiproliferative activities in human colon cancer cells SW480 at the testing concentration in 24 and $48 \mathrm{~h}$ using $60 \mu \mathrm{g}$ seed flour equivalent per $\mathrm{ml}$. The extract of milk thistle seed flour inhibited the cell growth of SW 480 by $17 \%$ in $48 \mathrm{~h}$. Therefore, the milk thistle seed flour potentially possessed antiproliferative activity in SW480 colon cancer cells. Antiproliferative activity against HCT116 colon cancer cells was also tested but did not show significant activity at $48 \mathrm{~h}$ using $60 \mu \mathrm{g}$ seed flour equivalent per $\mathrm{ml}$ (Fig. S4). Previous studies have shown antiproliferative effects from the components of these seed flours on different cancer cell types. (Singh et al., 2005; Deep and Agarwal, 2007; Imran et al., 2019). Changes in the concentration of the seed flour extracts may be needed to show more effects on the cells in this study.

\section{Conclusion}

This study identified chemicals in broccoli, carrot, and milk thistle seed flours that are recognized as bioactive compounds, such as glucoraphanin, luteolin, and silychristin, respectively. There were also compounds discovered that have been not been frequently identified, including 5-p-(6-caffeoyl-glucopyranosyl)- coumaroylquinic acid and methyl 5-(6-caffeoyl-glucopyranosyl)caffeoylquinic acid. The results also showed that broccoli, carrot, and milk thistle seed flour all possessed antioxidant activity. Milk thistle seed flour demonstrated the capacity to inhibit the growth of SW480 colon cancer cells in vitro and demonstrated cell toxicity effects on 3T3-L1 preadipocytes. These properties demonstrate potential health benefits and confer value to seed flour in the nutraceuticals market. Further studies of the bioactive properties of seed flours would be useful, such as continued investigation into antiproliferative activity.

\section{Supplementary Material}

Figure S1. Typical UHPLC chromatogram of the broccoli seed flour extract detected at $348 \mathrm{~nm}$.

Figure S2. Typical UHPLC chromatogram of the carrot seed flour extract detected at $348 \mathrm{~nm}$.

Figure S3. Typical UHPLC chromatogram of milk thistle seed flour extract detected at $348 \mathrm{~nm}$.

Figure S4. Antiproliferation of HCT116 colon cancer cells treated with seed flour extracts. Different letters within the same day represent significant difference $(P<0.05)$.

\section{References}

Álvarez-Fernández, M.A., Hornedo-Ortega, R., Cerezo, A.B., Troncoso, A.M., and García-Parrilla, M.C. (2016). Determination of nonantho- 
a

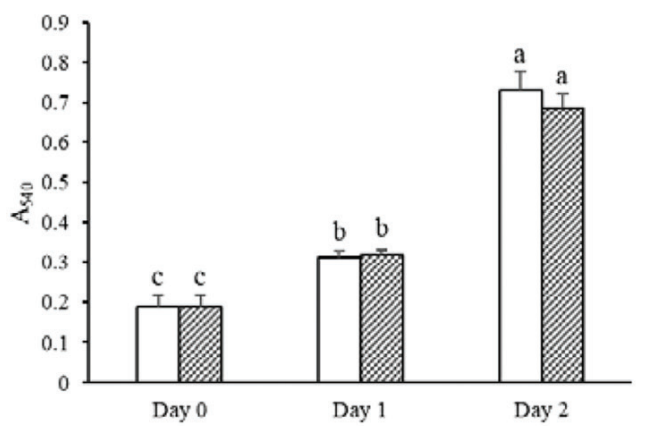

C

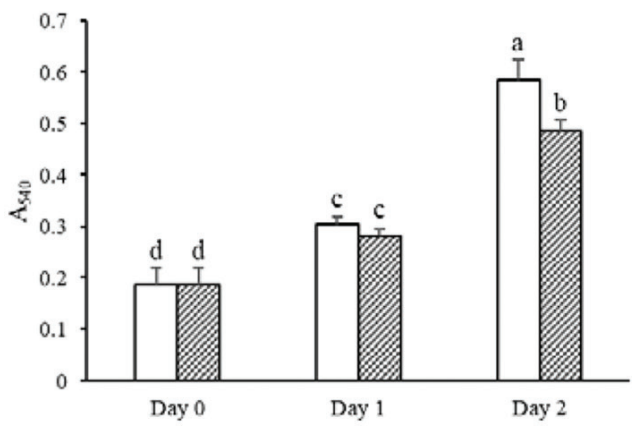

b

Carrot

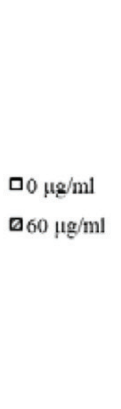

$\square_{0} \mu \mathrm{g} / \mathrm{ml}$

$060 \mu \mathrm{g} / \mathrm{ml}$

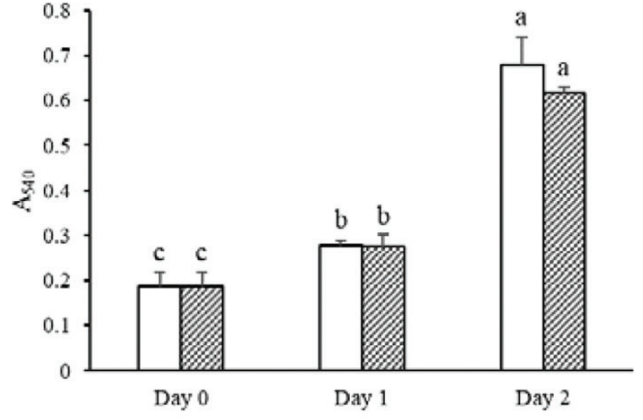

$\square 0 \mu \mathrm{g} / \mathrm{ml}$

$\Delta_{60} \mu \mathrm{g} / \mathrm{ml}$

Figure 5. Antiproliferation of SW480 colon cancer cells treated with seed flour extracts. Different letters within the same day represent significant difference $(P<0.05)$.

cyanin phenolic compounds using high-resolution mass spectrometry (UHPLC-Orbitrap-MS/MS) and impact of storage conditions in a beverage made from strawberry by fermentation. J. Agric. Food Chem. 64(6): 1367-1376.

Ayoub, M., de Camargo, A.C., and Shahidi, F. (2016). Antioxidants and bioactivities of free, esterified and insoluble-bound phenolics from berry seed meals. Food Chem. 197(Pt A): 221-232.

Balasundram, N., Sundram, K., and Samman, S. (2006). Phenolic compounds in plants and agri-industrial by-products: Antioxidant activity, occurrence, and potential uses. Food Chem. 99(1): 191-203.

Cheng, Z., Moore, J., and Yu, L. (2006). High-throughput relative DPPH radical scavenging capacity assay. J. Agric. Food Chem. 54(20): 74297436.

Choe, U., Li, Y., Gao, B., Yu, L., Wang, T.T., Sun, J., Chen, P., Liu, J., and Yu, L. (2018). Chemical Compositions of Cold-Pressed Broccoli, Carrot, and Cucumber Seed Flours and Their in Vitro Gut Microbiota Modulatory, Anti-inflammatory, and Free Radical Scavenging Properties. J. Agric. Food Chem. 66(35): 9309-9317.

Choe, U., Li, Y., Gao, B., Yu, L., Wang, T.T., Sun, J., Chen, P., and Yu, L.L. (2019). The chemical composition of a cold-pressed milk thistle seed flour extract, and its potential health beneficial properties. Food Funct. 10(5): 2461-2470.

da Silva, J.K., Cazarin, C.B., Correa, L.C., Batista, Â.G., Furlan, C.P., Biasoto, A.C., Pereira, G.E., de Camargo, A.C., and Maróstica Junior, M.R. (2016). Bioactive compounds of juices from two Brazilian grape cultivars. J. Sci. Food Agric. 96(6): 1990-1996.

Damodaran, S., Parkin, K.L., and Fennema, O.R. (2008). Fennema's food chemistry (4th ed). CRC Press/Taylor \& Francis, Boca Raton.

De la Torre-Carbot, K., Jauregui, O., Gimeno, E., Castellote, A.I., LamuelaRaventós, R.M., and López-Sabater, M.C. (2005). Characterization and quantification of phenolic compounds in olive oils by solidphase extraction, HPLC-DAD, and HPLC-MS/MS. J. Agric. Food Chem. 53(11): 4331-4340.

Deep, G., and Agarwal, R. (2007). Chemopreventive efficacy of silymarin in skin and prostate cancer. Integr. Cancer Ther. 6(2): 130-145.

Fahey, J.W., Haristoy, X., Dolan, P.M., Kensler, T.W., Scholtus, I., Stephenson, K.K., Talalay, P., and Lozniewski, A. (2002). Sulforaphane inhibits extracellular, intracellular, and antibiotic-resistant strains of Helicobacter pylori and prevents benzo [a] pyrene-induced stomach tumors. PNAS. 99(11): 7610-7615.

Gironés-Vilaplana, A., Moreno, D.A., and García-Viguera, C. (2014). Phytochemistry and biological activity of Spanish Citrus fruits. Food Funct. 5(4): 764-772.

Higashi, Y., Noma, K., Yoshizumi, M., and Kihara, Y. (2009). Endothelial function and oxidative stress in cardiovascular diseases. Circulation. 73(3): 411-418.

Imran, M., Rauf, A., Abu-Izneid, T., Nadeem, M., Shariati, M., Khan, I., Imran, A., Orhan, I., Rizwan, M., Atif, M., Gondal, T., and Mubarak, M. (2019). Luteolin, a flavonoid, as an anticancer agent: a review. Biomed Pharmacother. 112: 108612.

Inbaraj, B.S., Lu, H., Kao, T., and Chen, B. (2010). Simultaneous determination of phenolic acids and flavonoids in Lycium barbarum Linnaeus by HPLC-DAD-ESI-MS. J. Pharm. Biomed. Anal. 51(3): 549-556.

Juge, N., Mithen, R., and Traka, M. (2007). Molecular basis for chemoprevention by sulforaphane: a comprehensive review. Cell. Mol. Life Sci. 64(9): 1105.

Kelebek, H. (2016). LC-DAD-ESI-MS/MS characterization of phenolic constituents in Turkish black tea: Effect of infusion time and temperature. Food Chem. 204: 227-238.

Kumarasamy, Y., Nahar, L., Byres, M., Delazar, A., and Sarker, S.D. (2005). The assessment of biological activities associated with the major constituents of the methanol extract of 'wild carrot' (Daucus carota L.) seeds. J. Herb Pharmacother. 5(1): 61-72.

Li, W., Han, J., Li, Z., Li, X., Zhou, S., and Liu, C. (2008). Preparative chromatographic purification of diastereomers of silybin and their quantification in human plasma by liquid chromatography-tandem mass spectrometry. J. Chromatrog. B. 862(1-2): 51-57.

Li, Y., Zhang, T., Korkaya, H., Liu, S., Lee, H.-F., Newman, B., Yu, Y., Clouthier, 
S.G., Schwartz, S.J., and Wicha, M.S. (2010). Sulforaphane, a dietary component of broccoli/broccoli sprouts, inhibits breast cancer stem cells. Clin. Cancer Res. 16(9): 2580-2590.

Li, Z.T., Zhang, F.X., Chen, W.W., Chen, M.H., Tang, X.Y., Ye, M.N., Yao, Z.H., Yao, X.S., and Dai, Y. (2020). Characterization of chemical components of Periplocae Cortex and their metabolites in rats using ultraperformance liquid chromatography coupled with quadrupole timeof-flight mass spectrometry. Biomed. Chromatogr. 34(4): e4807.

Lobo, V., Patil, A., Phatak, A., and Chandra, N. (2010). Free radicals, antioxidants, and functional foods: impact on human health. Pharmacogn. Rev. 4(8): 118-126.

Mateen, S., Tyagi, A., Agarwal, C., Singh, R.P., and Agarwal, R. (2010). Silibinin inhibits human nonsmall cell lung cancer cell growth through cell-cycle arrest by modulating expression and function of key cellcycle regulators. Mol. Carcinog. 49(3): 247-258.

McWalter, G.K., Higgins, L.G., McLellan, L.I., Henderson, C.J., Song, L., Thornalley, P.J., Itoh, K., Yamamoto, M., and Hayes, J.D. (2004). Transcription factor Nrf2 is essential for induction of NAD (P) H: quinone oxidoreductase 1 , glutathione $\mathrm{S}$-transferases, and glutamate cysteine ligase by broccoli seeds and isothiocyanates. J. Nutr. 134(12): 3499S3506S.

Moore, J., Cheng, Z., Su, L., and Yu, L. (2006). Effects of solid-state enzymatic treatments on the antioxidant properties of wheat bran. J. Agric. Food Chem. 54(24): 9032-9045.

Moreno, D.A., Carvajal, M., López-Berenguer, C., and García-Viguera, C. (2006). Chemical and biological characterisation of nutraceutical compounds of broccoli. J. Pharm. Biomed. Anal. 41(5): 1508-1522.

Mudge, E., Paley, L., Schieber, A., and Brown, P.N. (2015). Optimization and single-laboratory validation of a method for the determination of flavonolignans in milk thistle seeds by high-performance liquid chromatography with ultraviolet detection. Anal. Bioanal. Chem. 407(25): 7657-7666.

Omar, A.A., Hadad, G.M., and Badr, J.M. (2012). First detailed quantification of silymarin components in the leaves of Silybum marianum cultivated in Egypt during different growth stages. Acta Chromatogr. 24(3): 463-474.

Oszmiański, J., Lachowicz, S., Gorzelany, J., and Matłok, N. (2018). The effect of different maturity stages on phytochemical composition and antioxidant capacity of cranberry cultivars. Eur. Res. Food Tech. 244(4): 705-719.

Parry, J., Cheng, Z., Moore, J., and Yu, L. (2008). Fatty Acid Composition, Antioxidant Properties, and Antiproliferative Capacity of Selected Cold-Pressed Seed Flours. J. Am. Oil Chem. Soc. 85(5): 457-464.

Paz-Elizur, T., Sevilya, Z., Leitner-Dagan, Y., Elinger, D., Roisman, L.C., and Livneh, Z. (2008). DNA repair of oxidative DNA damage in human carcinogenesis: potential application for cancer risk assessment and prevention. Cancer Lett. 266(1): 60-72.

Rains, J.L., and Jain, S.K. (2011). Oxidative stress, insulin signaling, and diabetes. Free Rad. Biol. Med. 50(5): 567-575.

Rochfort, S.J., Trenerry, V.C., Imsic, M., Panozzo, J., and Jones, R. (2008). Class targeted metabolomics: ESI ion trap screening methods for glucosinolates based on MSn fragmentation. Phytochemistry. 69(8) 1671-1679.

Sánchez-Rangel, J.C., Benavides, J., Heredia, J.B., Cisneros-Zevallos, L., and Jacobo-Velázquez, D.A. (2013). The Folin-Ciocalteau assy revisited: improvement of its specificity for total phenolic content determination. Anal. Methods. 5: 5990-5999.

Shao, Y., Jiang, J., Ran, L., Lu, C., Wei, C., and Wang, Y. (2014). Analysis of flavonoids and hydroxycinnamic acid derivatives in rapeseeds (Brassica napus L. var. napus) by HPLC-PDA-ESI (-)-MS n/HRMS. J. Agric. Food Chem. 62(13): 2935-2945.

Shibano, M., Lin, A.-S., Itokawa, H., and Lee, K.-H. (2007). Separation and characterization of active flavonolignans of Silybum marianum by liquid chromatography connected with hybrid ion-trap and time-offlight mass spectrometry (LC-MS/IT-TOF). J. Nat. Prod. 70(9): 14241428

Singh, K., Singh, N., Chandy, A., and Manigauha, A. (2012). In vivo antioxidant and hepatoprotective activity of methanolic extracts of Daucus carota seeds in experimental animals. Asian Pac. J. Trop. Biomed. 2(5): 385-388.

Singh, S.V., Srivastava, S.K., Choi, S., Lew, K.L., Antosiewicz, J., Xiao, D., Zeng Y., Watkins, S.C., Johnson, C.S., and Trump, D.L. (2005). Sulforaphaneinduced cell death in human prostate cancer cells is initiated by reactive oxygen species. J. Biol. Chem. 280(20): 19911-19924.

Smith, M.A., Rottkamp, C.A., Nunomura, A., Raina, A.K., and Perry, G. (2000). Oxidative stress in Alzheimer's disease. Biochimica et Biophysica Acta (BBA). 1502(1): 139-144.

Stevanato, R., Fabris, S., and Momo, F. (2004). New enzymatic method for the determination of total phenolic content in tea and wine. J. Agric. Food Chem. 52(20): 6287-6293.

Vasudevan, M., Gunnam, K.K., and Parle, M. (2006). Antinociceptive and anti-inflammatory properties of Daucus carota seeds extract. J. Health Sci. 52(5): 598-606.

Velasco, P., Francisco, M., Moreno, D.A., Ferreres, F., García-Viguera, C., and Cartea, M.E. (2011). Phytochemical fingerprinting of vegetable Brassica oleracea and Brassica napus by simultaneous identification of glucosinolates and phenolics. Phytochem. Anal. 22(2): 144-152.

Wallace, S.N., Carrier, D.J., and Clausen, E.C. (2005). Batch solvent extraction of flavanolignans from milk thistle (Silybum marianum L. Gaertner). Phytochem. Anal. 16(1): 7-16.

Wang, C., Zhang, N., Wang, Z., Qi, Z., Zhu, H., Zheng, B., Li, P., and Liu, J. (2017). Nontargeted metabolomic analysis of four different parts of Platycodon grandiflorum grown in northeast China. Molecules. 22(8): 1280.

Willems, J.L., Khamis, M.M., Saeid, W.M., Purves, R.W., Katselis, G., Low, N.H., and El-Aneed, A. (2016). Analysis of a series of chlorogenic acid isomers using differential ion mobility and tandem mass spectrometry. Anal. Chim. Acta. 933: 164-174.

Xiao-Long, H., Dan, W., Jun, S., Liang-Zi, F., Du-Zhun, Z., and Shui-Han, Z. (2019). $\alpha$-Glucosidase Inhibitory Activity-guided Identification of Compounds from Clerodendrum bungei Steud by HPLC-ESI-QTOFMS/MS. DCM. 2(1): 41-49. 